\title{
A Management Rule of Thumb in Property-Liability Insurance
}

\author{
Martin Eling, Thomas Parnitzke, Hato Schmeiser \\ Institute of Insurance Economics, University of St. Gallen, Kirchlistrasse 2, \\ 9010 St. Gallen, Switzerland, martin.eling@unisg.ch
}

\section{Introduction}

Due to substantial changes in competition, capital market conditions, and supervisory frameworks, holistic analysis of an insurance company's assets and liabilities takes on special relevance. An important tool in this context is dynamic financial analysis (DFA). DFA is a systematic approach to financial modeling in which financial figures are projected under a variety of possible scenarios by showing how outcomes are affected by changing internal and/or external factors. The discussion in Europe about new risk-based capital standards (Solvency II project) and the development of International Financial Reporting Standards (IFRS), as well as expanding catastrophe claims, have made DFA an useful tool for cash flow projection and decision making, especially in the non-life and reinsurance businesses (for an overview, see [2]).

Some issues in implementing a DFA system have not been considered in the DFA literature yet. One of these is the integration of management strategies in DFA, which is the aim of this paper. Although addressing this issue has been recognized as necessary in the quest to improve DFA (see, e.g., [4], pp. 11-12; $[2]$, p. 518), there is very little literature on the subject. [5] and [3] present theoretical discussions of the issue, but their aim is not to show practical implementations or to evaluate implications for DFA decision making.

The aim of this paper is to implement management strategies in DFA and study their effects on a property-liability insurer's risk and return position. We use performance measures that reflect both risk and return of these strategies in a multi-period context. Thus, the aim is to compare DFA with and without the implementation of specific management strategies so as to provide insight for an insurer's long-term planning process.

Our starting point will be a DFA framework that encompasses only the main elements of a property-liability insurance company (Sect. 2). Then, in Sect. 3, we develop typical management reactions to the company's financial situation. Sect. 4 contains a DFA simulation study to test the management strategies and examine their effects on risk and return. We conclude in Sect. 5. 
In this paper, we present the findings for a basic model framework only. For an extended version of the model, and additional management strategies, the reader is referred to [6], which also provides a detailed description of the applied performance measures as well as exhaustive numerical results and robustness tests.

\section{Model Framework}

With $E C$, we denote the equity capital of the insurance company and $E$ stands for the company's earnings. For a time period $t \in T$, the following basic relation for development of the equity capital is obtained:

$$
E C_{t}=E C_{t-1}+E_{t} .
$$

The earnings $E_{t}$ per period are comprised of the investment result $I_{t}$ and the underwriting result $U_{t}$ :

$$
E_{t}=I_{t}+U_{t} .
$$

On the asset side, high-risk and low-risk investments can be taken into account. High-risk investments typically consist of stocks or high-yield bonds; low-risk investments are usually government bonds or money market instruments. The portion of the high-risk investment in the time period $t$ is given by $\alpha_{t-1}$. The rate of return of the high-risk investment in $t$ is denoted by $r_{1 t}$ and the return of the low-risk investment in $t$ is given by $r_{2 t}$. The rate of return of the company's investment portfolio in $t, r_{p t}$, is denoted by:

$$
r_{p t}=\alpha_{t-1} r_{1 t}+\left(1-\alpha_{t-1}\right) r_{2 t} .
$$

The company's investment result can be calculated by multiplying the portfolio return by the funds available for investment, i.e., the equity capital and the received premiums $P_{t-1}$ less the acquisition expenses $E x_{t-1}^{P}$ :

$$
I_{t}=r_{p t}\left(E C_{t-1}+P_{t-1}-E x_{t-1}^{P}\right) .
$$

The other major portion of the insurance company's result is generated by the underwriting business. We denote $\beta_{t-1}$ as the company's portion of the associated relevant market volume in $t$, assuming that $\beta=1$ represents the entire underwriting market accessible to the insurance company. The volume of this underwriting market is denoted by $M V$. Hence, the total premium income can be obtained from:

$$
P_{t-1}=\beta_{t-1} M V .
$$

Claims are denoted by $C$; expenses by $E x$. Expenses consist of the acquisition costs $E x_{t-1}^{P}$ and claim settlement costs $E x_{t}^{C}$. Acquisition expenses are calculated as a proportion of the premiums $\left(E x_{t-1}^{P}=\gamma \beta_{t-1} M V\right)$, while the 
claim settlement costs depend directly on the claims incurred $\left(E x_{t}^{C}=\delta C_{t}\right)$. Thus, we obtain the underwriting result with the relation:

$$
U_{t}=P_{t-1}-C_{t}-E x_{t-1}^{P}-E x_{t}^{C} .
$$

This model has two variables that management can change at the beginning of each period $t$-the proportion invested in the risky investment $(\alpha)$ and market share in the underwriting business $(\beta)$.

\section{Management Strategies}

Management strategy arises out of a complex mixture of different business objectives (e.g., profit maximization, satisfaction of stakeholder demands, or maximization of the manager's own utility). Some strategies might require fast interventions in the event of a dangerous financial situation. Others will be less time-critical, e.g., growth targets or long-term profit maximization. Thus, management strategy can be various and multifaceted, depending on the actual situation of the enterprise and the aims of management.

A possible strategy is to reduce risk in a distressed situation so as to avoid insolvency. To define the solvency strategy, we set a level for equity capital such that when the capital falls below this level, a management reaction will be triggered. In the context of the European capital standards (Solvency I), the minimum capital required (MCR) can serve as this critical level. However, management will not wait to act until the equity capital falls under the MCR. Thus, we consider a safety loading of, e.g., $50 \%$ above this critical level. Following these considerations, the solvency strategy works as follows. For each point of time $(t=1, \ldots, T-1)$ we decrease $\alpha$ and $\beta$ about 0.05 when equity capital is below the minimum capital required plus a safety loading of $50 \%$.

An alternative is the growth strategy. This strategy combines the solvency strategy with a growth target for the underwriting business. Should the equity capital drop below the minimum capital required (MCR) plus the safety loading of $50 \%$, the same rules apply as in the solvency strategy. If the equity capital is above the trigger, we assume a growth of 0.05 in $\beta$.

\section{Numerical Example}

We analyze a time period of $T=5$ years. The parameters $\alpha$ and $\beta$ can be changed in discrete steps of 0.05 within the range of 0 and 1 at the beginning of each year. The market volume $(M V)$ of the underwriting market accessible to the insurance company is $€ 200$ million. Our model company has a portion of $\beta=0.2$ in the market. The expenses, which are contingent on premiums written, are given by $E x_{t-1}^{P}=0.05 \beta_{t-1} M V$.

Investment return is assumed to be normally distributed. The continuous rate of return has a mean of $5 \%(12 \%)$ and a standard deviation of $5 \%(20 \%)$ 
in the case of a low- (high-) risk investment. Hence, e.g., for the discrete risky rate of return, $r_{1 t}=\exp (N(0.12,0.20))-1$. The risk-free rate of return $r_{f}$ is $3 \%$. The claims $C_{t}$ are modeled by using random numbers generated from a lognormal distribution with a mean of $0.85 \beta_{t-1} M V$ and a standard deviation of $0.1 \beta_{t-1} M V$. The expenses of claim settlement are determined by a $5 \%$ proportion of the random claim amount $\left(E x_{t}^{C}=0.05 C_{t}\right)$.

For the asset allocation we use data from the German regulatory authority (BaFin). German property-liability insurance companies typically invest about $40 \%$ of their funds in high-risk investments such as stocks and highyield bonds, with the other $60 \%$ being invested in low-risk investments such as, e.g., government bonds or money market investments (see [1], Table 510). Thus we choose $\alpha=0.4$ as the starting point for the asset allocation.

Calculation of the minimum capital required follows the Solvency I rules used in the European Union. The minimum capital thresholds based on premiums are $18 \%$ of the first $€ 50$ million and $16 \%$ above that amount. The margin based on claims, which is $26 \%$ on the first $€ 35$ million and $23 \%$ above that amount, is used if this sum exceeds the minimum equity capital requirements determined by the premium-based calculation. Following these rules we determine a minimum capital required of $€ 8.84$ million for $t=0$ (i.e., maximum of $18 \% \times € 40$ million and $26 \% \times € 34$ million). To comply with the Solvency I rules, the insurance company is capitalized with $€ 14$ million in $t=0$. This capitalization corresponds to an equity to premium ratio of $35 \%$, which is a typical value for German property-liability insurance companies (see [1], Table 520).

The following simulation examples were calculated on the basis of a LatinHypercube simulation with 100,000 iterations (see [7]). The results are summarized in Table 1.

Table 1. Results

\begin{tabular}{ccccc}
\hline Measure & & No strategy & Solvency strategy & Growth strategy \\
\hline Return & $E(G)$ & 8.48 & 8.26 & 11.09 \\
Risk & $\sigma(G)$ & 4.21 & 4.35 & 6.03 \\
& $R P$ & $0.23 \%$ & $0.11 \%$ & $0.22 \%$ \\
Performance & $P_{1}$ & 2.01 & 1.90 & 1.84 \\
& $P_{2}$ & 18.35 & 36.53 & 24.86 \\
\hline Notes: & \multicolumn{4}{l}{} \\
$E(G)$ & $=$ Expected gain per annum $=\left(E\left(E C_{5}\right)-E C_{0}\right) / 5$ \\
$\sigma(G)$ & $=$ Standard deviation of gain per annum $=\sigma\left(E C_{5}\right) / 5$ \\
$R P$ & $=$ Ruin probability \\
$P_{1}$ & $=\left(E\left(E C_{5}\right)-E C_{0}\left(1+r_{f}\right)^{5}\right) / \sigma\left(E C_{5}\right)$ \\
$P_{2}$ & $=\left(E\left(E C_{5}\right)-E C_{0}\left(1+r_{f}\right)^{5}\right) / R P$
\end{tabular}


Looking at the simulation results in the case where no management strategy is applied, we find an expected gain $(E(G))$ of $€ 8.48$ million per year with a standard deviation $(\sigma(G))$ of $€ 4.21$ million. The ruin probability $(R P)$ is $0.23 \%$, which is far below the ruin probability required by international regulatory authorities. For example, Switzerland requires a level of $0.40 \%$. Thus our model company can be called safe.

The company becomes even safer if the solvency strategy is applied. While the return remains nearly unchanged (the expected gain decreases about $3 \%$ from $€ 8.48$ million to $€ 8.26$ million per year), we find much lower values for the ruin probability, which is now $0.11 \%$. This is less than $48 \%$ of the value in the case where no management strategy is applied. Thus the solvency strategy is able to avoid most insolvencies without much effect on return. This also leads to much higher performance measures based on ruin probability (denoted as $P_{2}$ in Table 1) compared to the results in the "no strategy" case. The value of $P_{2}(36.53)$ is almost two times higher than that achieved with no strategy (18.35). Obviously, the solvency strategy is capable of reducing downside risk effectively and thus provides valuable insolvency protection.

The growth strategy is more flexible than the solvency strategy. The expected gain per annum for this strategy amounts to 11.09 million, $31 \%$ above the 8.48 million obtained when no management strategy is applied. The ruin probability $(0.22 \%)$ is sligthly lower and thus $P_{2}$ is higher compared with the "no strategy" case. In comparison to the solvency strategy the growth strategy is suitable for those managers pursuing a higher return level and who are willing to accept a higher risk.

Interestingly, for both strategies risk is not reduced if both the positive and the negative deviations from the expected value are taken into account. For example the standard deviation of the solvency strategy is $3 \%$ higher than with no strategy ( $€ 4.35$ million per year versus $€ 4.21$ million per year). This is because reducing the participation in insurance business and the fraction of risky investment changes the level of earnings among different time periods, which results in an increased standard deviation. Because of the higher standard deviation and the reduced return, the performance measure based on standard deviation (denoted as $P_{1}$ in Table 1) is slightly lower with the solvency strategy than in the "no strategy" case.

\section{Conclusion}

We implemented management strategies in DFA and studied their effects on a property-liability insurer's risk and return. We found that the solvency strategy, which reduces the volatility of investments and underwriting business in the event of a bad financial situation, is a reasonable strategy for managers who want to protect the company from becoming insolvent. Our numerical examples show that the ruin probability can be effectively delimited without affecting return too much. The growth strategy - combining the solvency 
strategy with a growth target in the insurance business - is an alternative for managers pursuing a higher return than offered by the solvency strategy and who are also willing to take higher risks.

\section{References}

1. BaFin (2005) Jahresbericht 2004, Statistik der Bundesanstalt für Finanzdienstleistungsaufsicht - Erstversicherungsunternehmen. Bundesanstalt für Finanzdienstleistungsaufsicht, www.bafin.de

2. Blum P, Dacorogna M (2004) DFA-Dynamic Financial Analysis. In: Teugels J, Sundt B (eds.) Encyclopedia of Actuarial Science. John Wiley \& Sons, New York et al.

3. Brinkmann M, Gauß U, Heinke V (2005) Managementmodell. In: Lebensausschuss des DAV (ed.) Stochastisches Unternehmensmodell für deutsche Lebensversicherungen. Verlag Versicherungswirtschaft, Karlsruhe

4. D'Arcy SP, Gorvett RW, Herbers JA, Hettinger TE, Lehmann SG, Miller MJ (1997) Building a Public Access PC-Based DFA Model. Casualty Actuarial Society Forum, Summer(2)

5. Daykin CD, Pentikäinen T, Pesonen M (1994) Practical Risk Theory for Actuaries. Chapman \& Hall, London

6. Eling M, Parnitzke T, Schmeiser H (2006) Management Strategies and Dynamic Financial Analysis. Working Paper, University of St. Gallen, St. Gallen

7. McKay M, Conover W, Beckman R (1979) A Comparison of Three Methods for Selecting Values of Input Variables in the Analysis of Output from a Computer Code. Technometrics 21:239-245 